E.M. Kamaltynova ${ }^{1}$, I.A. Deev ${ }^{1}$, L.M. $\operatorname{Ogorodova}^{1}$, E. von Mutsius ${ }^{2}$, S. Illi $^{2}$, M.M. Fedotova $^{1}$, E.A. Karbainova ${ }^{1}$, D.S. Afanasyeva ${ }^{1}$

${ }^{1}$ Siberian State Medical University of the Federal Agency for Public Health and Human Services of the Federal Service on Surveillance in Healthcare, Tomsk, Russian Federation

${ }^{2}$ Academic teaching hospital of the Ludwig Maximilian University, Haunerschen Academic teaching hospital of pediatric surgery, Munich, Germany

\title{
Sensitization spread and skin sensitivity to histamine in children of school-age in Tomsk and Tomsk Region
}

Author affiliation:

Elena Mikhailovna Kamaltynova, MD, assistant professor of the intermediate level pediatrics department with a course in children's diseases at the medical faculty of the SibSMU

Address: 44, Karla Marxa Str., Tomsk, 634009, tel.: +7 (3822) 51-36-96, e-mail: eleant21@yandex.ru

Article received: 22.03.2013. Accepted for publication: 30.09.2013

Study of sensitization spread is crucial to the understanding of formation mechanisms of allergic diseases symptoms and development of prevention programs. However, this parameter has been studied very insufficiently in Russia. The aim of this trial is to study spread of sensitization to allergens and skin sensitivity to histamine in the populations of urban and rural schoolchildren using the method of skin prick test. Methods: the authors examined 2,290 urban and rural schoolchildren (1-11 grades). Mixed allergens of house dust mites, cockroach, fish, birch pollen, mixed weeds and cat hair were used for the allergy test. Results: the authors revealed spread of sensitization to various allergens in various age-sex groups of urban and rural schoolchildren in Tomsk Region. Conclusion: the trial revealed that sensitization spread and skin sensitivity to histamine was higher in urban schoolchildren than in their rural peers $(p<0.001)$. Lower sensitization spread index in rural schoolchildren may be caused the skin reactivity reduction.

Keywords: children, sensitization, spread.

Allergic diseases based on sensitization to allergens - atopic diseases - are the most widespread in children [1]. In 2004, the World Allergy Organization (EAACI) revised the nomenclature of terms of reactions causing symptoms of allergic diseases; atopic disease was defined as the "increase in the level of $\mathrm{IgE}$ antibodies in response to low doses of allergens, which further development of such typical diseases, as asthma, rhinitis, and eczema" [2]. This definition describes not only peculiarities of immune reactivity, but also implies further development of clinical symptoms. In this context, atopic disease is the crucial risk factor of development of allergic diseases.

A sensitized patient may have positive results of allergic tests to certain allergens, which have never provoked disease symptoms before, possibly, due to immunity (natural tolerance) to the certain antigen or insufficient level of IgE antibodies for clinical symptoms of the disease to manifest themselves in the patient. Moreover, some patients do not have symptoms (idiopathic or after immune therapy), but still feature positive results of allergic tests; this indicates development of immunity (acquired tolerance) to allergens.

According to some authors, $30-50 \%$ of children in industrially developed countries have sensitization, but not all of them have symptoms of allergic diseases, which indicate that allergy is not the only factor responsible for the development of these disorders $[1,3]$. Concurrent increase in the rate of both atopic diseases and allergic sensitization has been observed in the recent decades. Most researchers consider these conditions to be interconnected, as considerable variations in population genetics cannot develop in such a short period of time. The main cause of increase in the rate of allergic diseases may be the change of ecological factors. It remains 
unclear how often allergic diseases are caused by atopic disease and how often the symptoms that are traditionally seen as typical allergic manifestations are actually connected with allergy. The best studied risk factors of allergic sensitization development are hereditary susceptibility, influence of environmental factors (air pollution), urban lifestyle, smoking parents and high concentrations of inhalation allergens in living spaces. However, these factors did not result in the increase in the spread of bronchial asthma symptoms despite the $45 \%$ increase in sensitization spread within the last 10 years [4].

The simplest, though highly informative and sensitive method of sensitization detection is skin prick test (SPT), which is widely used in clinical and epidemiologic trials. Formation of papule in response to allergen is the result of complex immunologic interaction resulting in local histamine release [5]. Skin histamine sensitivity at SPT is usually evaluated as positive control, although sometimes it is analyzed as a separate result. However, this variable is also affected by changing environmental factors, like nasal and bronchial hyper-reactivity, and contributes to the analysis of conducted trials [6].

Study of sensitization spread is important to understanding formation mechanisms of symptoms of allergic diseases and developing allergy prevention programs [7]. Sensitization spread in the school-age children in Russia is unknown.

The aim of this trial is to study spread of skin sensitivity to allergens and histamine in populations of urban and rural schoolchildren with the help of SPT.

\section{Patients and methods}

The trial protocol was reviewed and approved by the Local Committee on Ethics at the SEI HPE "SibSMU" of the Federal Service on Surveillance in Healthcare, Department of Health of Tomsk Region, Department of Education of the Tomsk city government and Department of General Education of the Tomsk Region government.

Design of the trial: full-design cross-sectional trial in 2 samples of schoolchildren - urban (Tomsk) and rural (Tomsk Region).

Tomsk Region is a subject of the Russian Federation incorporated into the Siberian Federal District. Length of the region from north to south is ca. $600 \mathrm{~km}$, from west to east $-780 \mathrm{~km}$. Most territory is taiga and bogs, difficult of access. The main river is Ob. Population of the region is ca. 1,045,500 people; $70.2 \%$ of them are urban residents. The population is mostly comprised of Russians (90.8\%). Population density is $3.3 / \mathrm{km}^{2}$. The region features acutely continental climate with prolonged winter and short and rather hot summer. The average temperature is $0.6^{\circ} \mathrm{C}$.

Examination of the urban sample was conducted on the basis of 2 randomly selected schools, of the rural sample - on the basis of 5 schools (due to low population size and in order to achieve sample capacity comparable to the urban sample). Rural districts were as far from Tomsk as 100$400 \mathrm{~km}$.

In order to prevent systematic errors due to confounding factors, we formed sufficiently large groups ( $>1,000$ schoolchildren per group) comparable on the basis of all parameters (sex, age, ethnicity etc.) and used the same methods of detecting influence of the factors under study, that are not susceptible to systematic errors.

Inclusion criteria: all children of grades 1-11 present at school at the time of examination without exclusion criteria.

Exclusion criteria: no informed consent of parents/tutors; negative reaction of a schoolchild to the test; intake of antihistamine and hormone drugs at the time of examination; anaphylactic reactions in anamnesis.

The main examination procedures were conducted on the basis of secondary schools of general education in Tomsk and Tomsk Region.

The examination procedures were conducted in the following succession: 
- Distribution of leaflets and informed consent blanks among parents/tutors for information and signing.

- Medical history taking (specification of whether antihistamine and/or corticosteroid drugs were being taken at the moment of examination and of anaphylactic reactions).

- SPT with allergens.

We had preliminarily trained employees taking part in the trial how to conduct SPT and instructed them on the first aid regulations in case of undesirable phenomena associated with this diagnostic technique. In order to rule out errors associated with interpretation of results, SPT in an urban sample and a rural sample was conducted by the same employees (pediatricians).

The statistical investigation involved results of examination of 2,290 schoolchildren. 264 schoolchildren were not present at school at the time of examination, 98 schoolchildren did not have informed consent, 123 schoolchildren were not willing to undergo examination, 23 schoolchildren took medicines. Therefore, the study included data of $81.8 \%$ children of the expected sample; 1,249 out of them $(54.5 \%)$ were urban residents, $1,041(27.3 \%)$ - rural residents; $1,104(48.2 \%)$ boys $1,186(51.8 \%)$ girls (tb. 1). Cat hair allergic test was not conducted at 2 rural schools (428 children) for technical reasons; we allowed for that in the mathematical data manipulation. Trial period: October-April 2009-2010.

Table 1. General description of urban and rural populations of children (the tb. features results of allergic tests for papule diameter $\geq 3 \mathrm{~mm}$ only).

\begin{tabular}{|c|c|c|c|c|c|c|c|}
\hline \multirow[t]{2}{*}{ Property } & \multicolumn{3}{|c|}{ Urban population } & \multicolumn{3}{|c|}{ Rural population } & \multirow[t]{2}{*}{$\mathbf{p}^{*}$} \\
\hline & $\mathrm{N}$ & $\mathrm{n}$ & $\%$ & $\mathrm{~N}$ & $\mathrm{n}$ & $\%$ & \\
\hline Girls & 1,249 & 682 & 54.6 & 1,041 & 504 & 48.4 & 0.003 \\
\hline Grade $($ mean \pm StD) & 1,249 & 5.5 & \pm 3.0 & 612 & 5.5 & \pm 3.2 & $0.829 \#$ \\
\hline \multicolumn{8}{|l|}{ SPT } \\
\hline 1 or more positive tests & 1,249 & 169 & 15.69 & 1,041 & 88 & 6.37 & $<0.001$ \\
\hline $\begin{array}{l}\text { Number of SPTs }+: \\
0 \\
1 \\
\geq 2\end{array}$ & 1,249 & $\begin{array}{l}1,024 \\
126 \\
99 \\
\end{array}$ & $\begin{array}{l}81.99 \\
10.07 \\
7.93 \\
\end{array}$ & 612 & $\begin{array}{l}574 \\
23 \\
15 \\
\end{array}$ & $\begin{array}{l}93.97 \\
3.76 \\
2.45 \\
\end{array}$ & $<0.001^{\wedge}$ \\
\hline Inhalation & 1,249 & 225 & 18.01 & 1,041 & 38 & 6.21 & $<0.001$ \\
\hline Perennial & 1,249 & 182 & 14.57 & 1,041 & 33 & 5.39 & $<0.001$ \\
\hline Seasonal & 1,249 & 90 & 7.21 & 1,041 & 32 & 3.07 & $<0.001$ \\
\hline Mixed house dust mites & 1,249 & 99 & 7.93 & 1,041 & 47 & 4.51 & 0.000 \\
\hline Cat hair & 1,249 & 101 & 8.09 & 612 & 17 & 2.78 & $<0.001$ \\
\hline Cockroach allergen & 1,249 & 46 & 3.68 & 1,041 & 31 & 2.98 & 0.35 \\
\hline Birch pollen & 1,249 & 56 & 4.48 & 1,041 & 24 & 2.31 & $<0.001$ \\
\hline Mixed weeds & 1,249 & 61 & 4.88 & 1,041 & 17 & 1.63 & $<0.001$ \\
\hline Fish allergen & 1,249 & 27 & 2.16 & 1,041 & 16 & 0.58 & 0.0015 \\
\hline $\begin{array}{l}\text { Cumulative allergen papule } \\
\text { diameter } \geq 4.5 \mathrm{~mm}\end{array}$ & 1,249 & 154 & 12.3 & 1,041 & 76 & 7.03 & $<0.001$ \\
\hline $\begin{array}{l}\text { Cumulative allergen papule } \\
\text { diameter } \geq 8.5 \mathrm{~mm}\end{array}$ & 1,249 & 85 & 6.81 & 1,041 & 34 & 3.27 & 0.0001 \\
\hline $\begin{array}{l}\text { Histamine papule diameter } \\
\text { (geometric mean / for } 95 \% \mathrm{CI} \text { ) }\end{array}$ & 254 & 6.05 & $\begin{array}{l}5.97- \\
6.13\end{array}$ & 128 & 5.29 & $\begin{array}{l}5.21- \\
5.37\end{array}$ & $<0.001 \#$ \\
\hline
\end{tabular}

Note. SPT - skin prick test, SPT+ - positive skin prick test, $\mathrm{N}$ - total amount of the studied children, $\mathrm{n}-$ amount of children with the property.

p for: ${ }^{*}-\chi^{2}, \#-$ Wilcoxon test, ${ }^{\wedge}-$ Mantel-Haenszel test for trend analysis. 


\section{Skin prick test}

Skin prick test was conducted in compliance with the international standards adopted for this type of study [8]. The following range of allergens was used: mixed allergens of house dust mites Dermatophagoides pteronyssinus and Dermatophagoides farina, cat hair, cockroach allergen, birch pollen, mixed allergens of weed pollen and fish allergen; positive control (histamine of $10 \mathrm{mg} / \mathrm{ml}$ concentration); negative control (salin), manufactured by ALK-Abelló (Spain). Application site (forearm, internal surface) was treated with $70 \%$ ethanol. Small drops of allergens were sprayed on skin $20 \mathrm{~mm}$ apart one by one. Then we made perpendicular punctures through drops with sterile scarificators (penetration depth $-1 \mathrm{~mm}$ ) (Allergopharma, Germany), individual for each patient and preparation. Local reaction was appraised after 15 minutes. We measured the largest papule diameter and the diameter perpendicular to the former diameter. Both parameters were registered; we also used the following formula to calculate the average diameter:

(the largest diameter + the diameter perpendicular to the former diameter) $/ 2$

We interpreted results with papule diameter $\geq 3 \mathrm{~mm}$ in case of negative 'negative control' and positive 'positive control'. Atopic index was calculated as an amount of individual positive SPTs and classified as low (1-2 positive results) or high ( 3 and more positive results). Cumulative papule size was calculated as the sum of diameters of all the patient's papules. Cumulative papule size $>8.5 \mathrm{~mm}$ was considered an indicator of intense atopic reaction.

Statistical analysis was conducted by the scientific group of asthma and allergy research (Haunerschen children's clinic of the Ludwig Maximilian Munich University, Germany) using software suite SAS. The accepted difference significance level (p) for comparison of groups was $<0.05$. We used Wilcoxon test for nonparametric spread of the compared parameters and Kruskal-Wallis test for simultaneous analysis of 2 variables. We used Pearson $\chi^{2}$ test to compare qualitative parameters and Mantel-Haenszel $\chi^{2}$ test for trend analysis.

Table 2. Sensitization spread in children of different age and gender (data for children with papule size $\geq 3 \mathrm{~mm}$ ).

\begin{tabular}{|c|c|c|c|c|c|c|c|c|c|c|c|c|c|c|}
\hline \multirow[t]{2}{*}{ Age } & \multicolumn{2}{|c|}{$\geq 1$ positive $S P T$} & \multicolumn{2}{|c|}{ Mixed HD mites } & \multicolumn{2}{|c|}{ Cat hair } & \multicolumn{2}{|c|}{ Cockroach allergen } & \multicolumn{2}{|c|}{ Birch pollen } & \multicolumn{2}{|c|}{ Mixed weed pollen } & \multicolumn{2}{|c|}{ Fish allergen } \\
\hline & $\begin{array}{l}\mathbf{B}, \% \\
\mathrm{n} / \mathrm{N}\end{array}$ & $\begin{array}{l}\mathrm{G}, \% \\
\mathrm{n} / \mathrm{N}\end{array}$ & $\begin{array}{l}\mathrm{B}, \% \\
\mathrm{n} / \mathrm{N}\end{array}$ & $\begin{array}{l}\text { G, \% } \\
\text { n/N }\end{array}$ & $\begin{array}{l}\mathbf{B}, \% \\
\mathrm{n} / \mathbf{N}\end{array}$ & $\begin{array}{l}\text { G, \% } \\
\text { n/N }\end{array}$ & $\begin{array}{l}\mathrm{B}, \% \\
\mathrm{n} / \mathrm{N}\end{array}$ & $\begin{array}{l}\mathrm{G}, \% \\
\mathrm{n} / \mathrm{N}\end{array}$ & $\begin{array}{l}\mathrm{B}, \% \\
\mathrm{n} / \mathrm{N}\end{array}$ & $\begin{array}{l}\mathrm{G}, \% \\
\mathrm{n} / \mathrm{N}\end{array}$ & $\begin{array}{l}\mathrm{B}, \% \\
\mathrm{n} / \mathrm{N}\end{array}$ & $\begin{array}{l}\mathrm{G}, \% \\
\mathrm{n} / \mathbf{N}\end{array}$ & $\begin{array}{l}\mathrm{B}, \% \\
\mathrm{n} / \mathrm{N}\end{array}$ & $\begin{array}{l}\text { G, \% } \\
\text { n/N }\end{array}$ \\
\hline All children & $16.93^{*}$ & 12.21 & $7.61^{*}$ & 5.32 & 7.45 & 5.33 & 3.99 & 2.78 & $5.16^{*}$ & 1.93 & $4.17^{*}$ & 2.7 & 1.45 & 1.43 \\
\hline $6-10$ years of & $\frac{150 / 886}{14.46^{*}}$ & $\begin{array}{c}119 / 975 \\
8.77\end{array}$ & $\frac{84 / 1,008}{6.46^{*}}$ & $\frac{62 / 1,144}{2.96}$ & $\frac{66 / 877}{6.46}$ & $\begin{array}{c}52 / 971 \\
3.80\end{array}$ & $\frac{44 / 1,080}{2.07}$ & $\frac{33 / 1,144}{1.48}$ & $\frac{57 / 1,080}{4.39^{*}}$ & $\frac{23 / 1,144}{1.97}$ & $\frac{46 / 1,080}{3.62}$ & $\frac{32 / 1,114}{1.97}$ & $\frac{16 / 1,080}{1.03}$ & $\frac{17 / 1,144}{1.23}$ \\
\hline age & $47 / 325$ & $30 / 342$ & $25 / 387$ & $12 / 406$ & $21 / 325$ & $13 / 342$ & $8 / 387$ & $6 / 406$ & $17 / 387$ & $8 / 406$ & $14 / 387$ & $8 / 406$ & $4 / 387$ & $5 / 406$ \\
\hline $\begin{array}{c}\text { 11-13 years } \\
\text { of age }\end{array}$ & $\begin{array}{c}17.36 \\
42 / 242\end{array}$ & $\begin{array}{c}9.82 \\
28 / 285\end{array}$ & $\begin{array}{c}5.26 \\
16 / 304\end{array}$ & $\begin{array}{c}5.47 \\
18 / 329\end{array}$ & $\begin{array}{c}7.85 \\
19 / 242\end{array}$ & $\begin{array}{c}4.56 \\
13 / 285\end{array}$ & $\begin{array}{c}2.63 \\
8 / 304\end{array}$ & $\begin{array}{c}2.13 \\
7 / 329\end{array}$ & $\begin{array}{c}6.25^{*} \\
19 / 304\end{array}$ & $\begin{array}{c}2.13 \\
7 / 329\end{array}$ & $\begin{array}{c}5.59 \\
17 / 304\end{array}$ & $\begin{array}{c}1.82 \\
6 / 329\end{array}$ & $\begin{array}{c}0.99 \\
3 / 304\end{array}$ & $\begin{array}{c}0.91 \\
3 / 329\end{array}$ \\
\hline 14-18 years & 19.68 & 17.73 & 11.05 & 7.82 & 8.93 & 7.56 & 7.20 & 4.89 & $5.40^{*}$ & 1.96 & 3.86 & 4.40 & 2.31 & 2.20 \\
\hline of age & $61 / 310$ & $61 / 344$ & $43 / 389$ & $32 / 409$ & $26 / 310$ & $26 / 344$ & $28 / 389$ & $20 / 409$ & $21 / 389$ & $8 / 409$ & $15 / 389$ & $18 / 409$ & $9 / 389$ & $9 / 409$ \\
\hline $\mathrm{p}\left(\chi^{2}\right)$ & 0.2166 & 0.0287 & 0.0089 & 0.0090 & 0.6388 & 0.0714 & 0.0005 & 0.009 & 0.5509 & 0.9839 & 0.3925 & 0.0489 & 0.2316 & 0.3093 \\
\hline $\mathrm{p}(\mathrm{MH})$ & 0.0809 & 0.0078 & 0.0168 & 0.0022 & 0.3567 & 0.0289 & 0.0003 & 0.0036 & 0.5320 & 0.9880 & 0.8709 & 0.0352 & 0.1399 & 0.2524 \\
\hline
\end{tabular}

Note. SPT - skin prick test, $\mathrm{HD}$ - house dust, $\mathrm{B}$ - boys, G - girls, $\mathrm{n} / \mathrm{N}$ - amount of children with positive SPTs / amount of the studied children.

$\mathrm{p}(\mathrm{MH})$ - difference significance, according to the Mantel-Haenszel test for trend analysis; * $-\mathrm{p}<0.05$ for boys and girls.

\section{Trial results and discussion}

Sensitization spread in the general population of children was $11.22 \%$. We observed age and gender dependence in terms of SPT spread: positive allergic tests were prevalent in boys (tb. 2). Age sensitization spread increase was observed in girls, while its level in boys remained stable within the whole school age period. That is why significant differences in the spread of positive SPTs in schoolboys and schoolgirls were established only for the younger children; no significant differences were found in adolescents of different gender (see tb. 2). These data correlate well with higher asthma spread in smaller boys in comparison with girls. This 
difference becomes nonexistent at the age of 9-11 years; among people older than 11 years of age, asthma prevails in women. The factors regulating such atopic status alterations are unknown. The assumption that hormonal alterations taking place in puberty are the cause of this situation has not been proved [9].

Analysis of spread of sensitization to each allergen determined that the share of schoolchildren with sensitization to mixed allergens of house dust mites $(p<0.0001)$, cockroach $(p<0.0001)$, mixed weed pollen $(p=0.027)$ was increasing with age considerably; to cat hair $(p=0.0389)-$ less considerably; to birch pollen $(p=0.6174)$ and fish allergen $(p=0.0632)$ - no increase. Sensitization structure in different age-gender groups showed that the allergens used in the trial may conventionally be divided into 3 groups: I - sensitization to which increases with age considerably (mixed allergens of house dust mites and cockroaches); II - sensitization to which increases only in the population of girls (cat hair, mixed weed pollen); III - sensitization to which remained stable within the whole observation period (birch pollen and fish allergen).

Such sensitization formation peculiarities may depend not only on the macroorganism and environmental conditions, but also on antigenic properties of each allergen. Awareness that sensitization increases with age intensely to house dust mites and cockroach allergen - predictors of a severer course of bronchial asthma and allergic rhinitis - may promote development of modern and adequate methods of treatment and prevention of allergic diseases [10]. Lack of age dynamics in spread of sensitization to birch pollen and fish indicates that those children, who had already had sensitization to these allergens in the early school age, comprise a pollinosis or food allergy development risk group regardless of whether the child had had clinical manifestations by the time of examination or not. These groups of schoolchildren require intent observation by a doctor and preventive anti-allergic measures.

Spread of sensitization to all allergens under study, except cockroach allergen, was higher in urban schoolchildren in comparison with rural schoolchildren $(p<0.001)$ (see tb. 1).

Children with high atopic index were also prevalent in the population of urban schoolchildren $2.72 \%(34 / 1,249)$ and $1.15 \%(7 / 612) ; \mathrm{p}<0.05$. A significantly larger amount of children with cumulative papule size $\geq 8.5 \mathrm{~mm}$ also indicates higher sensitization level in urban population (see tb. 1) for all allergen groups: inhalation - 6.73\% $(84 / 1,249)$ in urban population and $2.12 \%$ $(13 / 612)$ in rural population, respectively, $p<0.0001$; perennial $-7.05 \%(88 / 1,249)$ and $2.45 \%$ $(15 / 612), \mathrm{p}<0.0001$; seasonal $-7.37 \%(92 / 1,249)$ and $3.27 \%(34 / 1,041), \mathrm{p}<0.0001$.

Studies of sensitization spread around the world showed that this parameter ranges from $1.7 \%$ in Ghana to $45.3 \%$ in Guangdong Province (China) [11]. Therefore, we revealed a relatively low sensitization spread in the population of schoolchildren under study; also, rural lifestyle is a protective factor against atopic disease development. Rural lifestyle's protective effect was registered in different countries and different continents $[1,12,13]$ due to closer contact with pets (cats and dogs) and presence of siblings [12, 14, 15]. The latest studies showed that consumption of raw milk and high content of microbes in drinking water are also associated with lesser risk if allergic sensitization $[16,17]$. Lower atopic disease spread is registered among the children, who had previously lived in socialist European countries. Sensitization spread was different, even if the compared populations of children lived in similar climatic and geographical conditions, but in different socioeconomic conditions. Thus, schoolchildren living in Karelia featured lower sensitization spread in comparison with their Finnish peers [18]. Comparison of sensitization spread among children of 0-2 years of age in Estonia and Sweden revealed that most children in Sweden had, along with atopic dermatitis symptoms, positive allergic tests, while in children with dermatitis symptoms in Estonia they were registered far rarer [19]. One of the assumptions accounting for the lower spread of positive SPT may be skin reactivity reduction, which is in direct correlation to the average histamine papule diameter.

Skin reactivity results were analyzed only in those children who had sensitization to 1 or more allergens. It has been established that schoolchildren had a significantly larger average histamine papule size in comparison with their rural peers $(6.05 \pm 1.3$ and $5.29 \pm 0.9 \mathrm{~mm}(\mathrm{p}<0.0001)$, respectively). No histamine papule size difference has been registered in boys and girls - 
$4.86 \pm 1.2$ and $4.97 \pm 1.29 \mathrm{~mm}(\mathrm{p}>0.05)$; however, skin histamine sensitivity increase in children was observed $(\mathrm{p}<0.0001)$.

The sensitization spread was also analyzed in terms of histamine papule size. Positive result was interpreted as ratio of the average allergen papule diameter to the average histamine papule diameter $\geq 0.5$ [6]. We obtained somewhat different results applying this approach. We established that spread of sensitization to birch pollen, fish and cat hair allergens did not differ in urban and rural residents, positive SPT to cockroaches and house dust were prevalent in rural population, to weed pollen - in urban population ( $\mathrm{tb}$. 3). These results were different from the results obtained applying classic method of SPT evaluation and included such notion as skin histamine sensitivity in the interpretation.

Table 3. Sensitization spread in urban and rural schoolchildren determined allowing for skin histamine sensitivity.

\begin{tabular}{|l|c|c|c|c|c|c|c|}
\hline \multirow{2}{*}{ Property } & \multicolumn{3}{|c|}{ Urban population } & \multicolumn{3}{c|}{ Rural population } & \multirow{2}{*}{ * * } \\
\cline { 2 - 7 } & $\mathrm{N}$ & $\mathrm{n}$ & $\%$ & $\mathrm{~N}$ & $\mathrm{n}$ & $\%$ & \\
\hline Mixed house dust mites & 258 & 98 & 37.98 & 128 & 65 & 50.78 & 0.016 \\
\hline Cat hair & 258 & 108 & 41.9 & 67 & 28 & 41.8 & 0.9918 \\
\hline Cockroach allergen & 258 & 44 & 17.5 & 128 & 43 & 33.59 & 0.0003 \\
\hline Birch pollen & 258 & 62 & 24.03 & 128 & 27 & 4.51 & 0.5189 \\
\hline Mixed weeds & 258 & 70 & 27.13 & 128 & 22 & 17.9 & 0.0309 \\
\hline Fish allergen & 258 & 27 & 10.47 & 128 & 11 & 8.59 & 0.5612 \\
\hline
\end{tabular}

Note. Positive skin prick test was interpreted as ratio of the average allergen papule diameter to the average histamine papule diameter $\geq 0.5$.

Skin histamine sensitivity may considerably alter SPT results. Thus, Italian researchers revealed that different sensitization spread in different period was connected with skin sensitivity change, not with its actual increase [6]. Skin histamine sensitivity reduction causes certain sensitization spread reduction. In our trial, rural children had lower skin histamine sensitization, which affected allergic test results. Moreover, along with antigen-antibody reaction, SPT results reflect influence of such factors as gender, general IgE level, helminth invasion and of other unknown or non-specific factors, which may alter skin reactivity, and therefore, distort allergic test results. Thus, the results obtained in the trial show spread of SPT to different allergens and in different age-gender groups of urban and rural schoolchildren of Tomsk Region. These results may be lower than due, as we used only 6 allergens for allergic testing; however, they reflect general trends of atopic disease spread without any doubt. Results of allergic testing were different from the traditional results in case SPTs were interpreted allowing for skin histamine sensitivity; this dictates need in further research. What causes skin reactivity suppression in rural children? There is a large amount of studies showing lower SPT spread in children living in natural helminthiasis nidi [22]. Low SPT spread in this case is due to skin reactivity reduction. Tomsk Region is the largest natural nidus of opisthorchiasis; its spread is considerably higher in rural areas; it may cause skin reactivity on the population level [23]. However, not only helminthiases cause skin sensitivity suppression. Thus, when comparing results of trials in Sweden and Estonia, we did not register helminth invasions; however, Estonian children featured lower spread of positive SPTs [24]. It appeared that this effect was to a considerable extent caused by higher children's morbidity with acute respiratory viral infections in Estonia and more frequent use of antibiotics, which results in intestinal microflora and immune response alterations. Thus, lower SPT spread in the rural population of children may be connected both with skin reactivity suppression due to considerable opisthorchiasis spread and higher spread of respiratory tract infections.

This trial was restricted by the use of the only sensitization marker - skin prick tests. The results of our trial might be supplemented with data obtained through other methods. 


\section{REFERENCES}

1. Asher M. I., Montefort S., Bjorksten et al. ISAAC Phase Three Study. Worldwide time trends in the prevalence of symptoms of asthma, allergic rhino conjunctivitis, and eczema in childhood. ISAAC Phases One and Three repeat muliticountry cross-sectional surveys. Lancet. 2006; 368: 733-743.

2. Johansson S. G., Bieber T., Dahl R. et al. Revised nomenclature for allergy for global use: Report of the Nomenclature Review Committee of the World Allergy Organization, October 2003. J Allergy Clin Immunol. 2004; 113 (5): 832-6.

3. Pearce N., Pekkanen J., Beasley R. How much asthma is really attributable to atopy? Thorax. 1999; 54 (3): 268-72.

4. Ronmark E., Bjerg A., Perzanowski M. et al. Major increase in allergic sensitization in schoolchildren from 1996 to 2006 in northern Sweden. J Allergy Clin Immunol. 2009; 124 (2): 357-63.

5. Carroll W. D., Lenney W., Child F. et al. Asthma severity and atopy: how clear is the relationship? Arch Dis Child. 2006; 91: 405-409.

6. Ronchetti R., Villa M. P., Pagani J. et al. Immediate skin reactivity to histamine and to allergens in cohorts of 9-year-old schoolchildren studied 16 years apart. Clin Exp Allergy. 2003; 33: $1232-1237$.

7. Bousquet J. et al. MeDALL (Mechanisms of the Development of ALLergy): an integrated approach from phenotypes to systems medicine. Allergy. 2011; 66: 596-604.

8. Dreborg S., Frew A. Allergen standardisation and skin tests. EAACI 1993 subcommittee on skin tests. Allergy. 1993; 14: 48-82.

9. Namazova-Baranova L. S., Ogorodova L. M., Tomilova A. Yu., Deev I. A. et al.

Pediatricheskaya farmakologiya - Pediatric pharmacology. 2009; 6 (3): 59-65.

10. Namazova-Baranova L. S., Antonova E. V., Deev I. A. et al. Epidemiologiya allergicheskikh boleznei. Allergiya u detei: ot teorii - k praktike / pod red. L.S. Namazovoi-Baranovoi [Epidemiology of Allergic Diseases. Allergies in Children: from Theory to Practice. Edited by L.S. Namazova-Baranova]. Moscow, Soyuz pediatrov Rossii, 2010-2011. pp. 166-199.

11. Vink N. M., Postma D. S., Schouten J. P. et al. Gender differences in asthma development and remission during transition through puberty: The Tracking Adolescents' Individual Lives Survey (TRAILS) study. J Allergy Clin Immunol. 2010; 126: 498-504.

12. Busse W. W. The National Institutes of Allergy and Infectious Diseases networks on asthma in inner-city children: An approachto improved care. J Allergy Clin Immunol. 2010; 125: 52937.

13. Weinmayr G., Weiland S. K., Bjorksten B. et al. Atopic Sensitization and the International Variation of Asthma Symptom Prevalence in Children. Am J Respir Crit Care Med. 2007; 176: 565-574.

14. Viinanen A., Munhbayarlah S., Zevgee T. et al. The protective effect of rural living against atopy in Mongolia. Allergy. 2007; 62: 272-280.

15. Remes S. T., Pekkanen J., Soininen L. et al. Does heredity modify the association between farming and allergy in children? Acta Paediatr. 2002; 91: 1163-1169.

16. Majkowska-Wojciechowska B., Pelka J., Korzon L. et al. Prevalence of allergy, patterns of allergic sensitization and allergy risk factors in rural and urban children. Allergy. 2007; 62: $1044-1050$.

17. Celedon J. C., Litonjua A. A., Ryan L. et al. Exposure to cat allergen, maternal history of asthma, and wheezing in first 5 years of life. Lancet. 2002; 360 (9335 № 7): 781-2.

18. Perkin M. R., Strachan D. P. Which aspects of the farming lifestyle explain the inverse association with childhood allergy? J Allergy Clin Immunol. 2006; 117 (6): 1374-81.

19. von Hertzen L., Laatikainen T., Pitkanen T. et al. Microbial content of drinking water in

Finnish and Russian Karelia — implications for atopy prevalence. Allergy. 2007; 62 (3): 288-92. 
20. Pekkarinen P. T., von Hertzen L., Laatikainen T. et al. A disparity in the association of asthma, rhinitis, and eczema with allergen-specific IgE between Finnish and Russian Karelia. Allergy. 2007; 62: 281-287.

21. Voor T., Julge K., Bottcher M. F. et al. Atopic sensitization and atopic dermatitis in Estonian and Swedish infants. Clin Exp Allergy. 2005; 35: 153-159.

22. Flohr C., Quinnell R. J., Britton J. Do helminth parasites protect against atopy and allergic disease? Clinical and Experimental Allergy. 2008; 39: 20-32.

23. Evdokimova T. A., Ogorodova L. M. Pediatriya - Pediatrics. 2005; 6: 12-17.

24. Ogorodova L. M., Freidin M. B., Fedorova O. S. et al. Byulleten' sibirskoi meditsiny Bulletin of siberian medicine. 2006; 4: 48-52.

25. Ogorodova L. M., Deev I. A., Fedorova O. S. et al. Voprosy sovremennoi pediatrii - Current pediatrics. 2011; 10 (3): 43-47.

26. Voor T., Julge K., Bottcher M. F. et al. Atopic sensitization and atopic dermatitis in Estonian and Swedish infants. Clin Exp Allergy. 2005; 35: 153-159. 